\title{
The Application of Conceptual Metonymy in Discourse Coherence
}

\author{
Zhengling Fu \\ College of International Studies, Southwest University \\ Chongqing 400715, China
}

Tel: 86-135-9419-4776 E-mail: rainbow9119@163.com

Received: May 2, 2016 Accepted: May 16, 2016 Published: May 19, 2016

doi:10.5296/ijele.v4i2.9485 URL: http://dx.doi.org/10.5296/ijele.v4i2.9485

\begin{abstract}
The action scenario of speech acts, put forward by Thornburg and Panther (1997) from the perspective of cognition, provides a good rationale for the cognitive function of metonymy. This paper will deal with the important role of metonymy in the generation and interpretation of discourse. The author of this paper is going to try to analyze the explanatory power of metonymy on discourse coherence from these viewpoints.
\end{abstract}

Keywords: conceptual metonymy, discourse coherence, speech act 


\section{Introduction}

Discourse coherence is one of the most difficult and the most complicated topics of the discourse analysis. It has become a focal problem in discourse analysis in the recent decades. Metonymy is traditionally viewed as a figure of speech that involves a process of substituting one linguistic expression for another. It was basically thought of as a matter of language, especially literary of figurative language. In the last decades, with the advent of cognitive linguistics, it is generally believed that metonymy as well as metaphor is more than a linguistic device; rather it is seen as a reasoning and referential process. Contemporary cognitive linguists generally view metonymy as fundamental to the structuring of the conceptual knowledge.

In the past years, scholars have approached discourse coherence from different perspectives, namely, semantics, pragmatics, and psychology, and much progress has been made in their own fields. However, it is noteworthy that little work has been done on coherence from the perspective of metonymy. We try to establish a link between discourse and cognition through various types of metonymic processes. Hence, metonymy is seen as a process that shapes and binds text to provide conceptual coherence to our textual experience. The introduction of metonymy into the field of discourse analysis should not be considered as a deviation from the traditional analyzing approaches. On the contrary, it should definitely bring new blood and enrichment for the discourse analysis researches.

\section{A Survey of Coherence}

Coherence is an essential concept in discourse analysis and a crucial mark for a text. In this part, we firstly focus our discussion on some crucial and fundamental terms that cannot be overlooked and that you cannot escape from.

\subsection{Text and Discourse}

Both text and discourse are results of communication between participants. Different scholars have different opinions on text and discourse. Some scholars define that text and discourse refer to both written language and spoken language. For others, text refers to the written language used in written form such as novel, poem, while discourse is the language used in spoken form such as speech and dialogue. Discourse is the umbrella term for either spoken or written communication beyond the sentence. Text is the basic means of this communication, be it spoken or written, a monologue or an interaction. The two separate terms, text and discourse, have, in fact, been related to two different but complimentary perspectives on language. In line with discourse analysis and text linguistics, text has often been used to refer to a static concept - the product of a process; whereas, discourse has been used to refer to a dynamic notion - the process of a text production and comprehension. Thus, discourse is a more embracing term that calls attention to the situated uses of text; it comprises both text and context. However, text is not just the product of discourse, as customarily assumed (cf. Brown and Yule 1983), that is, the actual (written or spoken) language unit product on the page. The notion of text has expanded from a descriptive structural to a procedural unit 
adopting situational factors into its scope. In this paper, the difference between discourse and text is neglected. Discourse and text are interchangeably used.

\subsection{Coherence}

Coherence is very complicated phenomenon; and it is very difficult to define. Since the notion of coherence is not well-defined, it requires explication. Intuitively, coherence is a semantic property of discourse, based on the interpretation of each sentence relative to the interpretation of other sentences (Van Dijik, 1977:93). Another definition is that coherence is the main principle if organization which is assumed to account for the underlying functional connectedness of a piece of spoken or written language (Crystal, 1985:33). Sanford and Garrod argue that coherence does not seem to be a property of text; rather it is property of mental representation even when it does not contain appropriate cohesion markers. They assume that coherence of a mental representation consists of a connected ideas based on appropriately interested discourse (Sanford and Garrod, 1981). A Chinese scholar Zhang Delu says that in a broad sense, coherence is a semantic concept which includes pragmatic factors (Zhang Delu, 2000). From the above definition, it can be easily learned that the complexity of the notion of coherence. The author of this paper agrees with such an opinion that coherence is not only the structural connectedness or formal concord of discourse, but also the extra-linguistic factors such as pragmatic, psychological and cognitive factors that are related to the interpretation of discourse.

\subsection{Classification of Coherence}

Generally speaking, coherence can be divided into the following two types: local coherence and global coherence.

Local coherence, i.e., the relation between a given constituent utterance and a prior discourse, essentially means that coherence in discourse is achieved through the perception of a limited set of links that may be found between the propositions expressed. "Local coherence" is another interpretation of cohesion theory.

Global coherence involves two important theories of global coherence, namely Van Dijik's "macro-structures", and Johnson Laird's "mental models".

Van Dijik's claim is that coherence discourse allow the deviation of a global semantic structure, termed macro-structure, which consists of a very small number of hierarchically organized macro-propositions.

A mental model is a symbolic representation of a body of knowledge, whose structure is isomorphic to that of the situation represented. Mental models are amoral, i.e., they are able to represent and integrate information derived from different kinds of sensory input, e.g. linguistic, visual, tactile, etc., as well as from word knowledge (Johnson-Laird 1989: 470). A mental modal of a discourse will typically incorporate not only knowledge which is directly expressed in that discourse, but also background knowledge and inferences necessary to comprehension. As the discourse proceeds, the model is continually updated, and possibly revised, in the light of incoming information. 
The argument of the two different propositions may overlap and yet not be co-referential. They are coherent according to mental representation. Therefore, it is a truth that coherence is closely related with people's cognition and psychology.

\subsection{The Nature of Coherence}

As defined in the above section, coherence refers to the perceptible integration of discourse elements into the holistic sense of a discourse by means of linguistic structure and/or pragmatic inference. If the integration is realized through the use of linguistic structure, there must be something visible in the connection of discourse elements; and if the integration is achieved through pragmatic inference, there must be something hidden under the surface structure of discourse to make the discourse a coherent whole. This is the characteristic of coherence being overt and covert.

By overt coherence, what is meant here is that the coherence is something available in the surface structure. Coherence of this type is relatively easy to identify. Therefore, methods for investigating overt coherence are mainly directed at the description of linguistic forma markets, or in other term, "discourse markets" (Lenk, 1998:56), equal in its broad sense to Halliday and Hasan's term "cohesion devices". Halliday and Hasan have made great contributions to the study of coherence in their cohesion analysis. Cohesion, which has been popularized by them, refers to the various linguistic means by which discourse elements "stick together", linking into large units of paragraphs, or stanzas, or chapters.

In the opinion of those who intend to account for the overt coherence of discourse, coherence is the structural connectedness or formal concord of discourse. However, a discourse with overt coherence is not necessarily and really coherent as far as the overall sense of discourse can be coherent. Why? The reason is that there is something covert, outside the linguistic form, to govern the overall sense. This is covert coherence. By covert coherence is meant that coherence is achieved not by using superficial markers as linguistic, grammatical devices, etc., but recourse to the components of context as the producer, the recipient, subject matter, culture, and so on (Stalpers 1988:87). Based on this sense, the methods for coherence analysis involve consideration of extra-linguistic factors such as pragmatic factors and psychological factors that are related to the interpretation of discourse.

\section{Cognitive View of Metonymy}

Metonymy is traditionally regarded as a figure of speech that involves a process of substituting one linguistic expression for another. It was basically thought of as a matter of language, especially literary or figurative language. This view of metonymy is reflected in standard definitions, which tend to describe metonymy as "a figure of speech that consists in using the name of one thing for that of something else with which it is associated." Here, metonymy is viewed as a relation in which one linguistic expression "stands for" another. In recent years, with the advent of cognitive linguistics, it has been recognized that the traditional view of metonymy is too narrow and that metonymy, like metaphor, has come to be recognized as a fundamental cognitive and linguistic phenomenon alongside metaphor 
(cf.Panther and Radden, 1999;Barcelona, 2000;Dirven and Porrings,2002).Metonymy is a conceptual tool that operates within"idealized cognitive models" or "domain matrices" (Lakoff 1987;Croft,1993). In this view, metonymy is defined as (Radden\&Kǒvecses,1999), which has been presented before. A cognitive process in which one conceptual entity, the vehicle, provides mental access to another conceptual entity, the target, within the same idealized cognitive model. The cognitive linguistics makes three assumptions about metonymy that is very different from traditional view:

1. Metonymy is a conceptual phenomenon;

2. Metonymy is a cognitive process;

3. Metonymy operates within the same idealized cognitive model.

In what follows, the author will talk about the three assumptions with examples. They are including a special case of metonymy what traditional rhetoricians have called synecdoche, where the part stands for the whole, as in the following.

\section{THE PART FOR THE WHOLE}

(6) The automobile is clogging our highways. (=the collection of automobiles)

(7) We need a couple of strong bodies for our team. (=strong people)

(8) There are a lot of good heads in the university. (=intelligent people)

(9) I've got a new set of wheels. (=car, motorcycle, etc.)

(10) We need some new blood in the organization. (=new people)

In these cases, as in the other cases of metonymy, one entity is being used to refer to another. Metaphor and metonymy are different kinds of processes. Metaphor is principally a way of conceiving of one thing in terms of another, and its primary function is understood. Metonymy, on the other hand, has primarily a referential function, that is, it allows using one entity to stand for another. But metonymy is not merely a referential device. It also serves the function of providing understanding. For example, in the case of the metonymy THE PART FOR THE WHOLE there are many parts that can stand for the whole. Which part can be picked out determines which aspect of the whole is being focused on. When one says that he needs some good heads on the project, he is using "good heads" to refer to "intelligent people". The point is not just to use a part (head) to stand for a whole (person) but rather to pick out a particular characteristic of the person, namely, intelligence, which is associated with the head. The same is true of other kinds of metonymies. When one says "The Times has not arrived at the press conference yet", he is using "The Times" not merely to refer to some reporter or other but also suggest the importance of the institution the reporter represents. So "The Times has not arrived for the press conference yet." means something different from "Steve Roberts has not arrived for the press conference yet.", even though Steve Roberts may be the Times' reporter in question.

Thus metonymy serves some of the same purposes that metaphor does, and in somewhat the 
same way, but it allows one to focus more specifically on certain aspects of what is being referred to. It is also like metaphor in that it is not just a poetic or rhetorical device. Nor is it just a matter of language. Metonymic concepts (like THE PART FOR THE WHOLE) are part of the ordinary and everyday way one thinks and acts as well as talks.

\section{Metonymy and Discourse Coherence}

\subsection{The Scenario Approach to Metonymy}

As far as scenario is concerned, it is necessary to refer to Sanford and Garrod. They (1981) assume that language understanding is a process in which linguistic input and a knowledge-based structure (or memory) interact. Their main interest is in describing how this interaction takes place. A crucial feature of their account is a view of how conceptual information must be stored in the mind, in order to be able to be utilized in the process of language understanding. Actually, the idea that language involves not only decoding linguistic information, but also contextual factors linked to stored conceptual information, is not a novel one. In fact, Sanford and Garrod owe much of their basic framework to the works of Minsky (1975), Norman et al.(1975) and especially Schank (e.g.Schank \& Abelson 1977). The author of this paper does not want to discuss those accounts here, but it is necessary to point out that they share the basic assumption that conceptual information is stored in the mind in a situation-based way, in modular or quasi-modular chunks. Minsky calls the chunk a "frame", Norman et al. call it a "schema" and Schank a "script". Thus, according to their accounts, the knowledge base consists of a large number of frames/schemata/scripts. Sharing this basic assumption, Sanford and Garrod propose their own account, in which each chunk of the knowledge base is called a "scenario". Their main idea is roughly as follows (cf. Matsui, 1998; Yongzhong Li, 2003e; 2004c): (i) the long-term memory is organized in a situation-based way and in chunks, each of which can be retrieved as a unit; (ii) hence, if an appropriate chunk, which they call a "scenario", has been successfully retrieved from a hearer's long term memory to form part of his mental model of a discourse at some stage before he encounters a bridging reference, a slot for the referent is most likely to be in the mental model; (iii) therefore, reference resolution will be rapid and automatic because the hearer does not make any inferential bridge involving a search for the reference in the whole general knowledge base, which is supposed to be much more time-consuming.

\subsection{Types of Speech Act Mmetonymies}

Different writers will classify speech act metonymies from various points of view, and here the author of this paper borrows the idea of Thornburg and Panther (1997) and try to classify them on the basis of three related components in the whole action scenario.

\section{The BEFORE component for whole scenario}

The component in BEFORE stage mainly includes the ability of the speaker wish of the hearer to ask the speaker to perform an action for a linguistic action.

For example: 


\section{Macrothink}

(18) "Don’t be absurd, darling, I can advance you any amount you ask for," said Caroline. "Don't you know I am a very wealthy woman?"

(19)Try not to worry so much. Would you like me to have a word with Stuart?

2. The CORE/RESULT component for whole scenario

The CORE/RESULT is the key stage of the whole scenario, which includes the obligation to perform an action for a linguistic action. In terms of speech act theory, this metonymy can also be called illocutionary effect for illocutionary act, which is a specific instance of the more general metonymy effect for cause. For example:

(20) Julie, you're wet. You must change.

(21)Do sit down, both of you. You must certainly play for us, if you will, Mr. er-.

3. The AFTER component for whole scenario.

This stage mainly involves a future action for a linguistic action. For example:

(22) “Oh, Rachel, don't you see, I can ask you to marry me now," he said huskily.

"You do care for me, dearest? You will say 'yes'?"

(23) I will come with you tomorrow, but more than what I cannot promise.

It is very common to find the metonymic expressions in literature. Metonymy, like other tropes, can add colors to the narration, and thus enhance the poetic effects of literature work. All these examples indicate the AFTER PART FOR THE WHOLE SCENARIO.

The above classification of speech act metonymies is made in light of the three stages of speech act scenario. The three different metonymies are in accord with more general metonymic principles, such as POTENTIALITY FOR ACTURALITY, MOTIVATION/REASON FOR ACTION, EFFECT FOR CAUSE, etc. Now let's give some examples to illustrate them:

\section{NECESSITY FOR MOTIVATION}

(24) He was passing her with an inclination of his head. "No," she said unsteadily. "I must speak to you, please!" he followed her into the room near by. [I must speak to you stands for I want to speak to you]

\section{POTENTIALITY OR MOTIVATION}

(25) “...I can lend you whatever money you require until we return.” [I can stands for I want] POTENTIALITY FOR ACYUALITY

(26) I can testify that, seen from the surrounding heights, it is a fairyland of lights that many shops are open and the windows of the others lit up. [I can testify stands for I testify]

(27) "I cannot let her down just like that, yet one day it will have to come. I can see that now." [I can see (=understand)that now stands for I see(=understand)] 
(28) Cuddy emitted a low soundless whistle. "That's a lot of change." "Yes, but I will get it." "You will be lucky." "You bet I am. I am on the right streak tonight, I can feel it." I can feel it stands for I feel it]

\section{EFFECT FOR CAUSE}

The general metonymy effect for cause can be illustrated by the more specific sub-case result for action, which is all-pervasive in language.

(29) Can I have hot chocolate with whipped cream? [have is the result of give]

(30) Please stand behind the yellow line. Have documents ready. (U.S Customs in an airport) [stand and have are the result of prior actions]

\section{FORM FOR CONTENT}

(31) "It may be as long as seven or eight months, but you will be married to me before that, June." "Oh, no!" even his attraction was powerless to affect her at that moment. "How can you mention such a thing?" [In asking how the legitimacy of the speech act comes about, the speaker implicitly rejects the legitimacy of the speech act and therefore it's content]

\section{Conclusion}

Coherence is an essential concept in discourse analysis and a crucial mark for a text. In this paper, the author makes a gross explanation towards discourse coherence through the metonymic perspective. The author focuses on the interpretation of the metonymic processes underlying the reader/hearer's comprehension of the discourse. Metonymy theory, esp. metonymic reasoning and inferencing have proved to be a powerful tool in illustrating and interpreting how the on-line construction of meaning can be achieved.

\section{Acknowledgement}

This research is financed by The Social Science Planning Project of Chongqing (2015YBYY134), The Higher Education and Teaching Reform Project of Chongqing (153030), and The Teacher and Teaching Development Project of Southwest University (SWFZ20150009)

\section{References}

Kǒvecses, Zoltán, \& Radden, Günter. (1998). Metonymy: Developing a Cognitive Linguistic View. Cognitive Linguistics, 9(1), 37-77.

Kǒvecses, Zoltán, \& Radden, Günter. (1999). Towards a Theory of Metonymy. In Panther, K-U., \& Günter Radden (eds.), Metonymy in Language and Thought. Amsterdam/Philadelphia: John Benjamins. pp.17-60. 
Laffal, J. (1965). Pathological and Normal Language. New York: Atherton Press.

Lakoff, George. (1987). Women, Fire and Dangerous Things: What Categories Reveal about the Mind. Chicago: University of Chicago Press.

Lakoff, G., \& M. Johnson. (1980). Metaphors We Live by. Chicago, IL: University of Chicago Press.

Lenk. (1998). Discourse markers and global coherence in conversation. Journal of Pragmatics, 30, 245-257.

Minsky, M. (1975). A framework for representing knowledge. In P. Wason (ed.), The Psychology of Computer Vision. New York: McGraw-Hill.

Panther, Klaus-Uwe, \& Günter Radden. (1999). Metonymy in Language and Thought. Amsterdam/Philadelphia:John Benjamins Publishing Company.

Panther, Klaus-Uwe, \& Linda Thornburg. (1998). A Cognitive Approach to Inferencing in Conversation. Journal of Pragmatics, 30, 755-769.

Sanford, Anthony J., \& Simon C. Garrod. (1981). Understanding Written Language: Explorations in Comprehension Beyond the Sentence. New York: Wiley.

Sanford, \& Garrod. (1981). Understanding Written Language. Chister:John Wiley.

Thornburg, Linda, \& Klaus-Uwe Panther. (1997). Speech Act Metonymies. In Wolf-Andreas Liebert, Gisela Redeker, \& Linda Waugh (eds.), Discourse and perspective in Cognitive Linguistics. Philadelphia:John Benjamins Publishing Company. pp.205-219.

Van Dijk. (1977). Text and Context Cambridge: CUP.

Van Dijk, \& Kintsh. (1983). Strategies of Discourse Comprehension. New York: Academic Press.

\section{Copyright Disclaimer}

Copyright for this article is retained by the author(s), with first publication rights granted to the journal.

This is an open-access article distributed under the terms and conditions of the Creative Commons Attribution license (http://creativecommons.org/licenses/by/3.0/). 